\title{
Systematic Review of Evidence and Treatment Approaches: Psychosocial and Mental Health Care for Children in War
}

\author{
Mark J.D. Jordans ${ }^{1,2}$, Wietse A. Tol ${ }^{1,2}$, Ivan H. Komproe ${ }^{1}$ \& Joop V.T.M. \\ de Jong ${ }^{2,3}$
}

${ }^{1}$ Healthnet TPO, Department of Public Health and Research, Amsterdam, the Netherlands.

E-mail: mjordans@healthnettpo.org

${ }^{2}$ VU University Medical Center, Amsterdam, the Netherlands

${ }^{3}$ Boston University School of Medicine, United States of America

\begin{abstract}
Background: There is a growing body of literature on interventions addressing psychosocial wellbeing and mental health of children affected by violence in low- and middle-income countries. Methods: This systematic review of PubMed, PsychINFO, and PILOTS identified 500 publications (1991-2008) on interventions. Results: Sixty-six publications (12 treatment outcome studies and 54 intervention descriptions, covering a range of treatment modalities) met inclusion criteria. Most interventions are evaluated positively, while some studies lack evidence for efficacy and effectiveness. Conclusion: Scarcity of rigorous studies, diversity of interventions, and mixed results of evaluations demonstrate a need to identify evidence-based interventions. The literature presents consensus on a number of treatment-related issues, yet the application remains limited across interventions.
\end{abstract}

Key Practitioner Message:

- There is a serious lack of rigorous studies evaluating psychosocial care for children affected by war.

- Though some treatment evaluation studies are promising, effect sizes of controlled studies are moderate and several studies have methodological flaws.

- Despite the PTSD bias of evaluation studies, papers describing treatment approaches support a paradigm shift from tertiary to primary care, with the main focus on community-based approaches.

- Most descriptive papers lack a comprehensive presentation of treatment modalities and either report single interventions or are limited to position statements.

Keywords: Systematic review; children; low- and middle-income countries; war; psychosocial; mental health; treatment; effectiveness; efficacy

\section{Introduction}

There is increasing evidence for the effectiveness of psychosocial and mental health treatment in low- and middle-income countries. A review by Patel and colleagues (2007) demonstrates that there is evidence for the effects of treatment for depression, antipsychotic drugs for schizophrenia, and brief interventions delivered by primary care staff for substance abuse. However, while the review highlights community-based rehabilitation models as a low-cost and integrative framework for care, it also points out the lack of evidence about effectiveness of such interventions (Patel et al., 2007). Other reviews echo the dearth of evidence for affordable child psychosocial and mental health interventions in low- and middle-income countries and complex emergencies (Morris et al., 2007; Barenbaum, Ruchkin, \& SchwabStone, 2004; Patel et al., 2008). For example, a worldwide systematic review on evidence-based primary prevention programs includes only studies in high-income countries (Flament et al., 2007).

Child mental health problems are a significant contributor to the global burden of disease (Remschmidt et al., 2007). Especially within low- and middle-income countries, there is a vast gap between child and adolescent mental health needs and the availability of resources, as well as lack of program development and policy to address the gap (Belfer, 2008; Patel et al., 2008). Additionally, considering the ample research on the harmful impact of armed conflicts and violence on children, the importance of psychosocial and mental health care for children cannot be overestimated (Stichick, 2001; Barenbaum et al., 2004; Williams, 2006). Though there is increasing consensus on mental health and psychosocial interventions in complex emergencies (IASC, 2007), there is a gap between child mental health needs and availability of evidence-based interventions (Morris et al., 2007; Patel et al., 2007). 
A small number of recent reviews have addressed the issue of children in complex emergencies, with particular attention paid to children in areas of armed conflict (Barenbaum et al., 2004; Kalsma-van Lith, 2007; Moss et al., 2006; Williams, 2006; Morris et al., 2007). These reviews emphasize (a) the lack of available assistance for children exposed to war and the need for development of assessment and interventions in their home countries (Moss et al., 2006; Barenbaum et al., 2004); (b) the need for combined attention to children's resilience and risk factors for developing severe mental health problems (Williams, 2006; Barenbaum et al., 2004) combined with a division between a curative mental health care approach and a developmental preventative approach (Kalsma-van Lith, 2007); (c) the scarcity of formulated specific therapy techniques and intervention effectiveness research for war-affected children (Barenbaum et al., 2004; Morris et al., 2007); and (d) the need for accessible, low-cost, systematic interventions (Moss et al., 2006; Williams, 2006; Barenbaum et al., 2004; Morris et al., 2007). In her review of community based mental health care in lowand middle-income countries Wiley-Exley (2007) calls for a further review of interventions targeting children. Although resourceful, the available reviews are neither rigorous nor systematic and/or are focused on the impact of armed conflict or the immediate response after emergencies. The current study is therefore the first to systematically review the literature on psychosocial and mental health interventions for children during and after war in low- and middle-income countries. The two aims of the review were (1) to provide an overview of the evidence-base for mental health and psychosocial treatment for children and adolescents in areas affected by violence and (2) to synthesize treatment descriptions and recommendations in order to summarise trends, including the non-researched, practical and grassroots context.

\section{Method}

The following databases were searched: PubMed, PsychINFO and PILOTS with the following search terms: ('child' or 'adolescent') and ('war' or 'armed conflict' or 'community violence') and ('intervention' or 'treatment') and ('psychosocial' or 'mental health'). In addition, a number of authors were approached for relevant publications. The search was limited to publication dates between 1991 and 2008. An initial search was performed on 15 August 2006, and repeated on 20 February 2008 to update results.

Articles were included for full review if they adhered to the following criteria: (a) publication involved description of, or recommendations for, psychosocial or mental health treatment or intervention programs with children specified as primary or secondary beneficiaries; (b) the article focused on low- and middle-income countries following definitions of the World Bank (2007), thereby excluding publications focusing on refugees in high-income countries; and (c) the publication was focused on protracted violence and long-term complex emergencies.

A four-step procedure for reviewing the search outcomes was followed. First, based on the above inclusion criteria, all search outcomes were assessed by title and/ or abstract. Second, if these criteria were met, or if the review of title and abstract was insufficient to exclude the study, the publication was selected for full review. Third, after full review, a final number of articles were included in the study. Fourth, all included articles were cross-referenced.

Actual review and analyses of the selected publications were conducted in several steps. First, articles were read by two authors of this paper (MJ and WT) and summarised in a pre-defined format. Second, information from the completed formats was transferred into a table with the following categories: intervention/treatment modalities (approach, focus, content/techniques, implementation steps), specification of target group and location, recommendations, cultural adaptations, classification as a clinical paper if describing an actual implemented intervention component, and a position paper if otherwise. Third, all treatment descriptions were categorised as targeting general well-being, psychosocial distress, psychopathology, or a combination. Interventions per category were subsequently grouped based on their primary treatment focus. Fourth, for the outcome studies the following categories were added: study (sample, design, instruments), outcomes and level of evidence $(1=$ randomised controlled trial; 2 = quasiexperimental design; $3=$ non-controlled design; 4 = case studies; adapted from Morris et al., 2007). All studies with an outlined methodology for evaluation, and reported results, were included in the treatment outcome table. Fifth, effect sizes (Cohen's $d$ ) were used to standardise the differences in outcome variables and allow for comparison of the different statistical measures. Effects sizes greater than 0.60 were classified as large, 0.30 to 0.60 as moderate, and less than 0.30 as small (Cohen, 1988). Finally, we summarised all entries on specific mention of (a) cultural adaptations and (b) evaluation components (for non outcome studies).

\section{Results}

The searches resulted in a total of 500 publications; PubMed returned 156 articles, PsychINFO 176, and PILOTS 86, 32 articles from cross-referencing and 50 articles through experts. Ninety-seven articles were selected for full review; 31 were excluded as not meeting the study criteria, leaving 66 for study inclusion (see Table 1). The articles describe activities in 18 countries

Table 1. Search outcomes

\begin{tabular}{|c|c|c|c|c|}
\hline Databases & $\begin{array}{l}\text { All outcomes: } \\
\text { Review, title } \\
\text { and abstract }\end{array}$ & Duplication & $\begin{array}{l}\text { Selected: } \\
\text { Review full } \\
\text { article }\end{array}$ & Included \\
\hline Pubmed & 156 & 0 & 13 & 11 \\
\hline Psychlnfo & 176 & 5 & 31 & 17 \\
\hline PILOTS & 86 & 13 & 16 & 6 \\
\hline $\begin{array}{l}\text { Authors' } \\
\text { database }\end{array}$ & 50 & 26 & 11 & 7 \\
\hline Cross refs & 32 & - & 27 & 25 \\
\hline Total & 500 & 44 & 97 & 66 \\
\hline
\end{tabular}

Note: Books may be referenced as 1 entry in 'all outcomes' column, but individual chapters as separate entries in the 'selected' or 'included' columns 
(Croatia, Uganda, Bosnia, West-Bank and Gaza, Ethiopia, Sierra Leone, Chechnya, Azerbaijan, Mozambique, Sri Lanka, Afghanistan, Iraq, Kosovo, Guatemala, Mexico, Rwanda, Zimbabwe, Angola) with $25.8 \%$ of the total publications and $41.6 \%$ of the outcome studies focusing on countries formerly part of Yugoslavia. Results are presented in order of the objectives outlined in the introduction.

To review the evidence base for treatment, publications describing an outcome study (with outlined methodology as a minimum criterion) are depicted in Table 2. In total 12 studies have been published with different levels of evidence. Two studies report randomised controlled trials (RCTs), 3 report non-randomised controlled studies, 6 report non-controlled studies, and 1 presents a case study. The interventions target symptoms of post-traumatic stress disorder (PTSD) and depression, and generic emotional, social and behavioral problems, as well as stressors. One study evaluates an intervention for individual children (Onyut et al., 2005) and one focuses on the parent-child dyad (Dybdahl, 2001a). All other studies evaluate group interventions. The majority of outcome studies focus on PTSD symptoms (8 studies, 66.7\%).

Eleven studies show patterns of positive treatment effects primarily reported as symptom reduction and/or increased protective factors (Stichick-Betancourt, 2005; Woodside, Santa Barbara, \& Benner, 1999; Bolton et al., 2007; Dybdahl, 2001a; Gordon et al., 2004; Layne et al., 2001; Cox et al., 2007; Loughry et al., 2006; Onyut et al., 2005; Paardekooper, 2002; Gupta \& Zimmer, 2008). Eight of these show improvements on multiple indicators, and two report sustained long-term effects at 9 months (Onyut et al., 2005) and 12 months (Woodside et al., 1999) post-treatment. Three of the studies also note negative outcomes: the risk of undermining the need for normality through intervention participation (Stichick-Betancourt, 2005), reduction of hope compared to control group (Loughry et al., 2006), and increased avoidance symptoms (Gupta \& Zimmer, 2008). One qualitative study failed to replicate positive quantitative findings when examining the same intervention (Cox et al., 2007). Three studies present no significant treatment effects of an emotion-focused coping group intervention, a creative workshop approach for depression, and a group crisis intervention for PTSD and depression symptoms (Paardekooper, 2002; Bolton et al., 2007; Thabet, Vostanis, \& Karim, 2005, respectively). The two reported RCTs give different results: Bolton and colleagues (2007) show the efficacy of group interpersonal therapy in reducing depression symptoms among 14 to 17 -year-old adolescent girls in Uganda, whereas a mother-child intervention in Bosnia has moderate positive effects on mothers' mental health, children's weight gain, and children's psychological functioning (Dybdahl, 2001a).

Comparisons of effect sizes provide a more nuanced picture of positive trends (see Table 2). Results from the RCTs demonstrate moderate treatment effects $(d=0.53$ in Bolton et al., 2007; between $d=0.33-0.54$ in Dybdahl, 2001a). The study by Loughry and colleagues (2006) shows small effect sizes for CBCL change $(d=0.27)$ and a moderate effect size for hope in the control group $(d=0.40)$. The studies of Paardekooper (2002) and Layne and colleagues (2001) give unclear findings in terms of effect sizes. The former demonstrates that if a cut-off threshold is used to evaluate treatment, no effect is detected despite reporting moderate to large effect sizes $(d=0.54-1.42)$. Layne and colleagues (2001) report large effect sizes for symptom change $(d=1.31-2.07)$ but no significant interaction effect for group membership (partial or full treatment participation). The results section of the study by Woodside and colleagues (1999) only allows for calculating the (small) effect size of one of the indicators for which treatment effect is stated $(d=.27$ for social distance). In the non-controlled studies, effect sizes are generally large $(d=0.6-2.4$ for Gordon et al., 2004; $d=2.25$ for Gupta \& Zimmer, 2008; 2.78 for Onyut et al., 2005). However, it should be noted that these are effect sizes of change not of treatment efficacy due to the lack of comparison of change scores with a control group.

Treatment focus and recommendations of the 66 studies were grouped in categories and subcategories (see Table 3 for detailed division of the publications over all categories and the 12 sub-categories). Category 1 comprises interventions targeting general well-being (18.6\% of the publications) with primary intervention foci including resilience $(8.6 \%)$, the child's social context $(4.3 \%)$, education $(4.3 \%)$, and reconciliation $(1.4 \%)$. Category 2 comprises interventions targeting psychosocial distress (30\% of the publications) with psychological $(22.9 \%)$, social $(5.7 \%)$, and traditional healing $(1.4 \%)$ as sub-categories. Category 3 comprises interventions targeting psychopathology $(18.6 \%$ of the publications) with primary intervention foci including PTSD $(12.9 \%)$, depression $(1.4 \%)$, or general mental health disorders (4.3\%). Seventeen publications (24.3\%) report interventions with multiple foci, which can be divided into two categories: multi-sectoral (also targeting issues other than psychosocial distress, e.g. reconstructing infrastructure) (18.6\%), and multi-levelled (simultaneously targeting different levels of distress) (5.7\%). The remaining six publications are not included in the categorization, five because they are reviews (Barenbaum et al., 2004; Morris et al., 2007; Kalsma-van Lith, 2007; Moss et al., 2006; Williams, 2006), and one because it does not fit in any of the categories (Hepburn, 2006).

A wide range of treatment modalities is reported (see Table 3). The most frequently mentioned treatment modalities used across the different categories are creative-expressive, recreational, and psycho-educational activities. Creative-expressive approaches include techniques such as story telling, drawing, writing, playing, role-playing, singing, dancing, playing music and performing psychodrama. Other treatment modalities are specific for the level of distress targeted such as counselling and family care targeting psychosocial distress, and psychotherapies targeting specific psychopathology such as PTSD. Few explicit therapies are reported: narrative exposure therapy (Schauer et al., 2004; Onyut et al., 2005), trauma/grief-focused group psychotherapy (Layne et al., 2001); dance and movement therapy (Harris, 2007), cognitive behavioural therapy (Jones et al., 2003), group interpersonal therapy (Bolton et al., 2007) and parent-child interaction therapy (Dybdahl, 2001a,b). Only one publication mentions the use of psychopharmacology (Jones et al., 


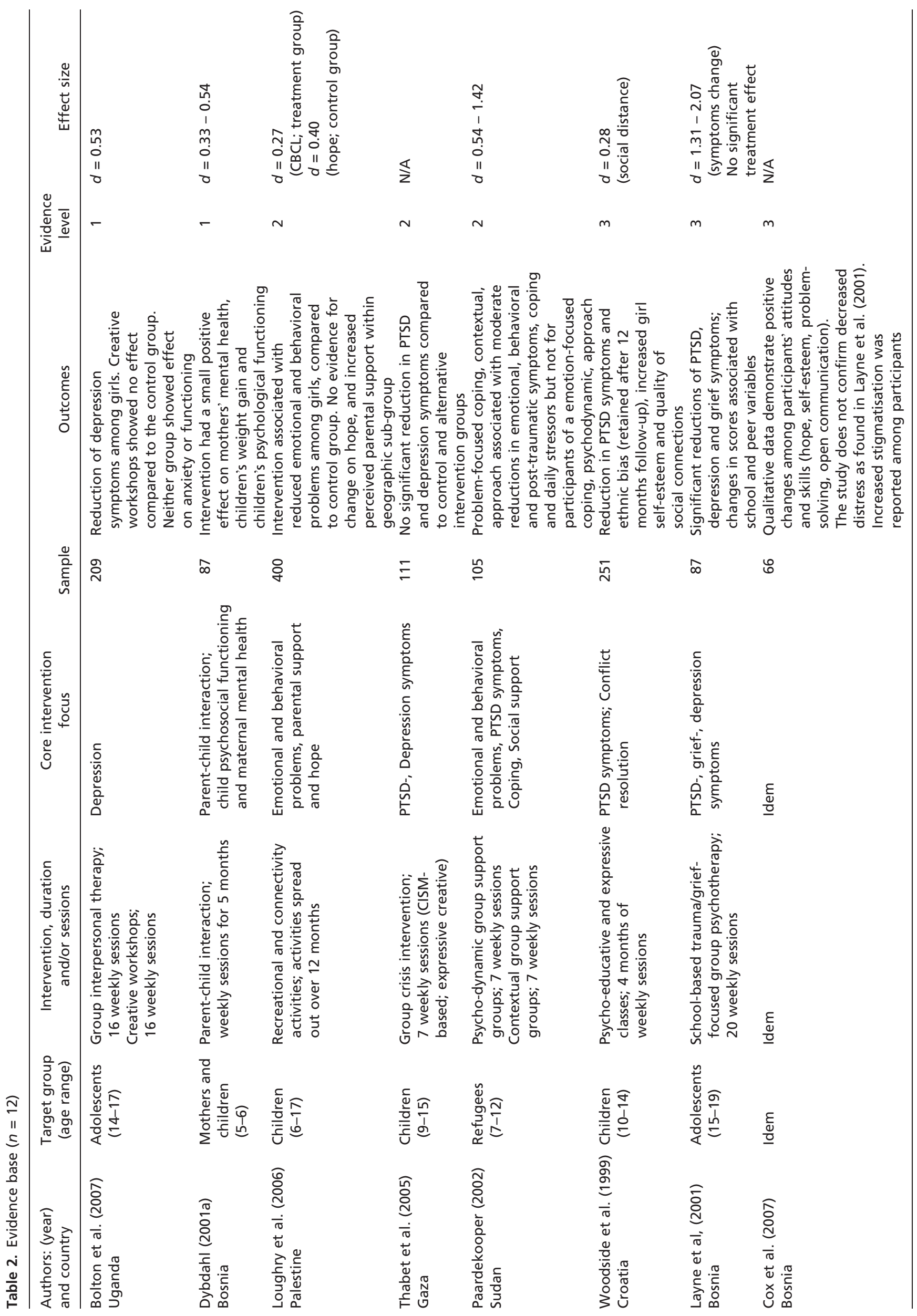




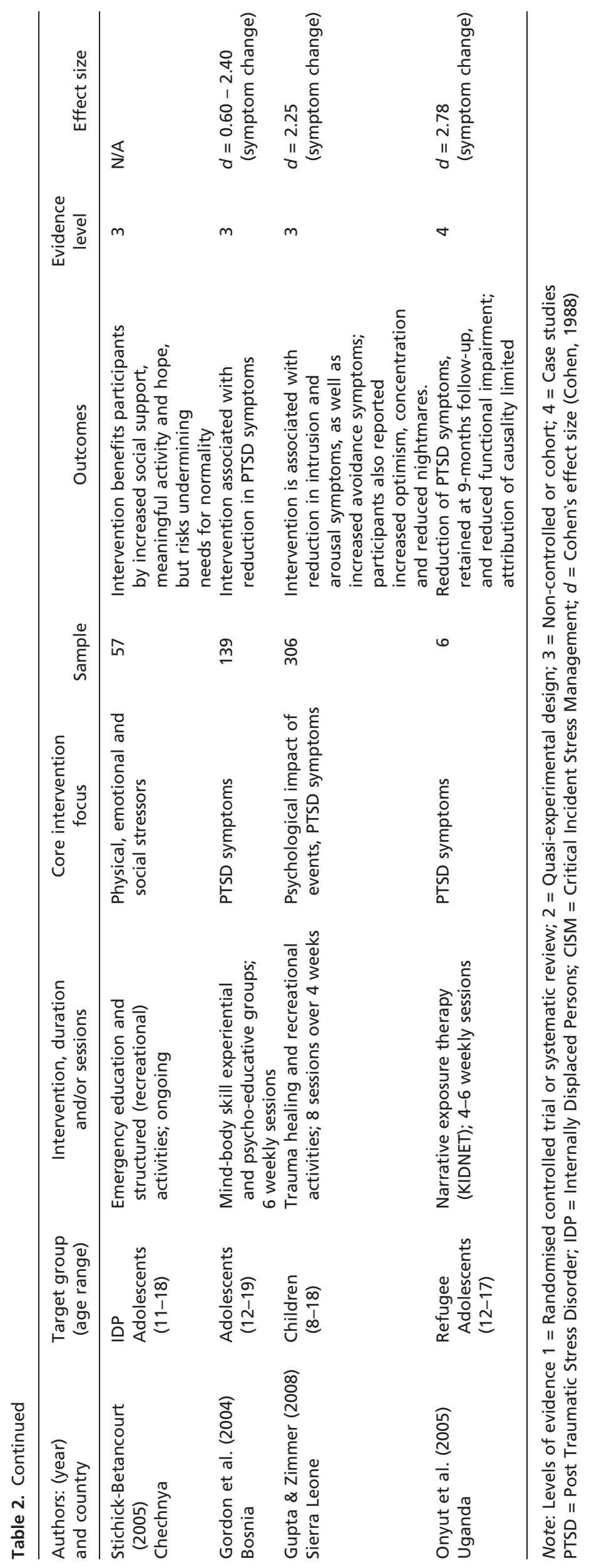


Table 3. Approaches and Interventions $(n=66)$

\begin{tabular}{|c|c|c|c|c|}
\hline Category & Focus & Author & $N(\%)$ & Treatment modalities \\
\hline \multirow[t]{4}{*}{$\begin{array}{l}\text { Interventions } \\
\text { targeting general } \\
\text { well-being }\end{array}$} & Context/social & $\begin{array}{l}\text { Boyden, 1994; } \\
\text { Kos \& Zemljak, 2007; } \\
\text { Ager, } 2006\end{array}$ & $3(4.3 \%)$ & $\begin{array}{l}\text { Indigenous coping } \\
\text { strategies } \\
\text { Teacher and health } \\
\text { worker sensitisation } \\
\text { Psycho-education } \\
\text { Community centre } \\
\text { Strengthen protective function } \\
\text { of family, access to resources } \\
\text { and social connections }\end{array}$ \\
\hline & $\begin{array}{l}\text { Resilience } \\
\text { (empowerment; } \\
\text { participation) }\end{array}$ & $\begin{array}{l}\text { Loughry et al., } 2006 \\
\text { Apfel \& Simon, 1996; } \\
\text { Kos \& Huzejrovic, 2003; } \\
\text { Kos \& Derviskadic-Jovanovic, } \\
\text { 1998; Hart, 2003; Kos, } 2005\end{array}$ & $6(8.6 \%)$ & $\begin{array}{l}\text { Recreational activities } \\
\text { Connectivity activities } \\
\text { Social support } \\
\text { Parental/caregiver support } \\
\text { Natural healing processes } \\
\text { Psycho-education } \\
\text { Child club activities } \\
\text { Youth/community mobilisation } \\
\text { for social action/ pro-social } \\
\text { engagement } \\
\text { Strengthening teachers } \\
\text { to support children }\end{array}$ \\
\hline & Education & $\begin{array}{l}\text { Stichick-Betancourt, } 2005 \\
\text { Kos \& Huzejrovic, 2003; } \\
\text { Arafat \& Musleh, } 2006\end{array}$ & $3(4.3 \%)$ & $\begin{array}{l}\text { Emergency education } \\
\text { Support/normalisation through } \\
\text { education, teachers \& } \\
\text { school environment } \\
\text { School as a multi-functional centre, } \\
\text { including recreational/non-formal, } \\
\text { expressive activities and } \\
\text { counselling/de-briefing services } \\
\text { Normalisation, empowerment } \\
\text { and social support }\end{array}$ \\
\hline & $\begin{array}{l}\text { Reconciliation/conflict } \\
\text { resolution }\end{array}$ & Woodside et al., 1999 & $1(1.4 \%)$ & $\begin{array}{l}\text { Peaceful living classes } \\
\text { (Non-violent-) communication skills }\end{array}$ \\
\hline \multirow[t]{2}{*}{$\begin{array}{l}\text { Interventions } \\
\text { targeting } \\
\text { psychosocial } \\
\text { distress }\end{array}$} & Psychological-focus & $\begin{array}{l}\text { Dybdahl, 2001a; Paardekooper, } \\
\text { 2002; Akhundov, 1999; } \\
\text { Amone-P'Olak, 2005; } \\
\text { Dybdahl, 2001b; Miller \& } \\
\text { Billings, 1994; Ayalon, 1998; } \\
\text { Chase et al., 1999; Minkowski, } \\
\text { 2000; Olij, 2005; Harris, 2007; } \\
\text { Simó-Algado et al., 2002; } \\
\text { Wertheim-Cahen, Euwema, \& } \\
\text { Nabarro, 2005; Kos, 2005; } \\
\text { Shaw \& Harris, 1994; } \\
\text { Yule et al., } 2003\end{array}$ & $16(22.9 \%)$ & $\begin{array}{l}\text { Awareness raising/trauma } \\
\text { sensitisation activities } \\
\text { Creative-expressive/creative } \\
\text { workshops } \\
\text { Dance and movement therapy } \\
\text { (expression \& de-somatising } \\
\text { memories) } \\
\text { Recreational activities \& sports } \\
\text { Parent-child interaction } \\
\text { Parental support/mother groups } \\
\text { Psycho-education } \\
\text { Coping strategies (problem-solving) } \\
\text { Counseling (trauma \& disclosure; } \\
\text { individual \& group; children \& } \\
\text { caregivers) } \\
\text { Strengthening of family system } \\
\text { Healing meditations and rituals } \\
\text { Occupational therapist using } \\
\text { creative-expressive techniques } \\
\text { Screening for severe MH problems/ } \\
\text { assessment } \\
\text { Residential trauma treatment program } \\
\text { followed by community reintegration }\end{array}$ \\
\hline & Social-focus & $\begin{array}{l}\text { Ayalon, 1998; } \\
\text { Boothby, 1992; } \\
\text { Lykes, 1994; Veale \& } \\
\text { Dona, } 2002\end{array}$ & $4(5.7 \%)$ & $\begin{array}{l}\text { Community-building } \\
\text { Social support } \\
\text { Restoration of social system } \\
\text { Family reunification } \\
\text { Awareness raising on community roles } \\
\text { of support } \\
\text { Income generation } \\
\text { Creative-expressive to 'break } \\
\text { culture of silence' } \\
\text { Integrate psychosocial support } \\
\text { within social/contextual and } \\
\text { child rights work }\end{array}$ \\
\hline
\end{tabular}


Table 3. Continued

\begin{tabular}{|c|c|c|}
\hline Category & Focus & Author \\
\hline & $\begin{array}{l}\text { Traditional } \\
\text { healing }\end{array}$ & Reynolds, 1996 \\
\hline $\begin{array}{l}\text { Interventions } \\
\text { targeting } \\
\text { psycho-pathology }\end{array}$ & Trauma/PTSD-focus & $\begin{array}{l}\text { Woodside et al., 1999; } \\
\text { Gordon et al., 2004; } \\
\text { Layne, 2001; } \\
\text { Onyut et al., 2005; } \\
\text { Cox et al., 2007; } \\
\text { Thabet et al., 2005; } \\
\text { Paardekooper, 2002; } \\
\text { Gupta \& Zimmer, 2008 } \\
\text { Schauer et al., } 2004\end{array}$ \\
\hline
\end{tabular}

Disorder-specific (non-PTSD)

General mental health

\section{Interventions} targeting different levels of well-being/ distress

\section{Multi-sectoral/} ecological

\section{Bolton et al., 2007}

Jones et al., 2003; Wexler, Branski, \& Kerem, 2006; Agani, 2005

De Berry, 2004; Joshi, 1998; Stichick, 2001; Tribe, 2004; Wessels \& Monteiro, 2006; Boothby \& Halprin, 2005, Boothby, 2006; Boothby 1996; Kostelny, 2006; Triplehorn \& Chen, 2006; Wessels, 2006; Wessels \& Monteiro, 2004; McKay, 2006;

$N(\%) \quad$ Treatment modalities

$1(1.4 \%) \quad$ Cleansing rituals

Healers system;

religious, cultural and ritual healing practices

9 (12.9\%) Recognition \& sharing of grief/loss Group trauma and grief therapy; Processing traumatic memories/ events and facilitate adaptive grieving Mind-body skills (experiential)

Psycho-education

Narrative exposure therapy (KIDNET)

Emotion-focused coping

Group crisis intervention (CISM-based)

Expressive-creative/

experiential techniques

Recreational-expressive techniques

Coping strategies

$1(1.4 \%) \quad$ Group interpersonal therapy

Creative workshops

$3(4.3 \%) \quad$ Mental health promotion/ awareness raising

CAMH: CBT; medication;

psycho-education

Prevention and rehabilitation

Multi-disciplinary CAMH: family

oriented, day programs

$13(18.6 \%) \quad$ Risk prevention

Integration of psychosocial support in non-medical sectors

Multi-sectoral coordination

Strengthening ecological

support systems

Restoring traditional beliefs

and practices

Creative-expressive/structured play

Parental-, caregivers- capacity

and support

Screening and support through health

and education workers

Social support/networks

Community mapping of needs

and resources

Youth focused activities: Life skills,

Peer dialogues, Community drama

Youth mobilisation for social action

('youth/community support projects')

Traditional-cultural ceremonies/healers

Community sensitisation/

public awareness

Apprenticeships/vocational -

skills training/income generation/ livelihood

Support reintegration and family reunification process of ex-child soldiers

Self-help groups

Counselling

Utilisation of community and cultural resources

Formal \& non-formal education (normalisation, life skills,

creative-expressive)

Combined focus on basic needs

and social-emotional needs

Reconciliation workshops

Community needs analyses

Child protection 
Table 3. Continued

\begin{tabular}{|c|c|c|c|c|}
\hline Category & Focus & Author & $N(\%)$ & Treatment modalities \\
\hline & $\begin{array}{l}\text { Multi-tiered/public } \\
\text { health }\end{array}$ & $\begin{array}{l}\text { Salzman et al., 2003; } \\
\text { Yule, 2000; Yule, 2002; } \\
\text { Brymer et al., } 2005\end{array}$ & $4(5.7 \%)$ & $\begin{array}{l}\text { Psycho-education, screening/ } \\
\text { assessment, Group trauma and } \\
\text { grief therapy, prosocial } \\
\text { community services } \\
\text { Awareness-raising, screening, } \\
\text { teacher-based support, } \\
\text { counselling centre } \\
\text { Recreational activities, psycho- } \\
\text { education, screening, counselling, } \\
\text { specialised } \\
\text { Integration of psychosocial care } \\
\text { within service systems, education, } \\
\text { health, social work }\end{array}$ \\
\hline \multirow[t]{2}{*}{ Others } & Different category & Hepburn, 2006 & $1(1.4 \%)$ & $\begin{array}{l}\text { Prevention and reunification of } \\
\text { separated children }\end{array}$ \\
\hline & Reviews & $\begin{array}{l}\text { Barenbaum et al., 2004; } \\
\text { Morris et al., 2007; } \\
\text { Kalsma-van Lith, 2007; } \\
\text { Moss et al., 2006; } \\
\text { Williams, } 2006\end{array}$ & $5(7.1 \%)$ & Presented in text \\
\hline
\end{tabular}

Note: Outcome studies are presented in bold font; CISM = Critical Incident Stress Management; CAMH = Child and Adolescent Mental Health

2003). Many interventions include a component related to the narration or expression of traumatic memories. Publications that present multi-sectoral interventions are mostly 'holistic' programs that integrate income generation, prevention of community risk factors, child protection, and community mobilisation incorporating psychosocial, mainly preventive, activities such as strengthening support systems, self-help groups, creative-expressive activities (for example Triplehorn \& Chen, 2006; Wessels \& Monteiro, 2006; De Berry, 2004; Boothby, 1996). Multi-levelled approaches are represented to a lesser degree and only one of these actually implemented a multi-level program (Saltzman et al., 2003). Comparable ingredients between the publications comprised awareness-raising or psychoeducation, screening or assessment, counselling or teacher-based support, and group based therapy or specialised services (Brymer, Stuvland, \& Medway, 2005; Yule, 2000, 2002; Saltzman et al., 2003).

When making a distinction between position papers (publications that focus on policy and do not present an actually implemented intervention or study thereof) and clinical papers (publications that do describe implementation of interventions or study thereof), it appears that $37.3 \%$ of the total publications are position papers (46.3\% when outcome studies are not included). The foci of the position papers are equally divided over the different categories, with the exception that the psychopathology category only includes one position paper.

In total, $79 \%(n=23)$ of the publications describing treatments report some level of evaluation or the described intervention has been studied in one of the outcome studies (see Table 4 for details). All present positive outcomes, ranging from symptom reduction to improved community mobilisation. Bearing in mind that publications that only described needs assessment were excluded from this study, we found that only a small number of intervention publications included needs assessments (de Berry, 2004; Arafat \& Musleh,
2006). Several of the position papers specifically mentioned the importance of evaluations and appropriate instrumentation to conduct such evaluations (Yule et al., 2003; Boothby 1996; Barenbaum et al., 2004; Morris et al., 2007). Some authors highlighted the challenges of evaluations or questioned the usefulness of effectiveness research (Hepburn, 2006; Kos \& Derviskadic-Jovanovic, 1998; Kos, 2005).

In summarising the trends of treatment modalities in low- and middle-income countries, we believe it is important to specifically review the extent of cultural adaptation. The majority $(67.7 \%)$ of the publications mention cultural adaptation as a recommendation or as a pre-requisite for implementation, and the publications without specific mention of cultural adaptation may still include an inherent adaptive component such as resilience, social-community approaches, conflict resolution, needs-based goal setting, and working with the family system (see Table 5). However, few give detailed accounts of any actual adaptations made. If adaptations are formulated, they are mainly in terms of (minor) inclusion of traditional components $(25.8 \%)$ within the healing process or in terms of collaborations with existing resources such as religious practices, rituals, and traditional healing. There is a trend that the effectiveness studies make less mention of adaptations, as well as those that are done in closer geographicalcultural distance to high-income countries, for example, Bosnia. A few authors call for adaptations of assessment and screening of mental health and psychosocial problems through locally developed and cross-culturally valid instruments (Bolton et al., 2007; Barenbaum et al., 2004; Yule et al., 2003; Jones et al., 2003).

\section{Discussion}

Following the aims of the study, the results are presented according to the level of evidence for the effect of 
Table 4. Evaluations in treatment description papers $(n=29)$

\begin{tabular}{|c|c|c|}
\hline Type of evaluation & $N(\%)$ & Reported outcomes \\
\hline $\begin{array}{l}\text { Interviews/ } \\
\text { self-reports }\end{array}$ & $\begin{array}{c}9 \\
(31.0 \%)\end{array}$ & $\begin{array}{l}\text { Less traumatic references in } \\
\text { drawings } \\
\text { Reduced symptoms } \\
\text { Increased community } \\
\text { mobilisation } \\
\text { Increased community integration } \\
\text { and social connection } \\
\text { Increased self-confidence or } \\
\text { self-esteem }\end{array}$ \\
\hline $\begin{array}{l}\text { Clinical } \\
\text { evaluations/case } \\
\text { reports }\end{array}$ & $\begin{array}{c}3 \\
(10.3 \%)\end{array}$ & $\begin{array}{l}\text { Change pattern of presented } \\
\text { disorders at CAMH intake } \\
\text { Reduced symptoms (PTSD, fear, } \\
\text { emotional problems, } \\
\text { aggression, intrusion, } \\
\text { depression, anxiety, sleeping } \\
\text { problems, bedwetting) }\end{array}$ \\
\hline $\begin{array}{l}\text { Anecdotal and } \\
\text { observation }\end{array}$ & $\begin{array}{c}7 \\
(24.1 \%)\end{array}$ & $\begin{array}{l}\text { Increased capacity of caretakers } \\
\text { Increased awareness of mental } \\
\text { health problems/changed } \\
\text { attitudes or decreased } \\
\text { stigmatisation } \\
\text { Improved school atmosphere } \\
\text { Traditional healers well } \\
\text { positioned to handle } \\
\text { troubled children } \\
\text { Able to express, share } \\
\text { experiences and } \\
\text { connect to feelings }\end{array}$ \\
\hline $\begin{array}{l}\text { Described in } \\
\text { one of the } \\
\text { outcome studies }\end{array}$ & $\begin{array}{c}4 \\
(13.8 \%)\end{array}$ & $\begin{array}{l}\text { Increased group cohesion } \\
\text { Reduced community tension } \\
\text { Improved life skills } \\
\text { Increased hope and belief } \\
\text { in peace } \\
\text { Improved parent-child relations }\end{array}$ \\
\hline
\end{tabular}

Note: This table does not include position papers; PTSD = Post Traumatic Stress Disorder; CAMH = Child and Adolescent Mental Health

intervention and the application and recommendations according to treatment modalities.

\section{Evidence base}

The few evaluation studies reviewed in this paper cover a range of interventions and conditions. Most interventions are evaluated positively on a number of indicators. At the same time there is a lack of evidence for the efficacy and effectiveness of certain interventions. Most studies lack scientific rigour to determine causality or the strength of reported change. A meta-analysis of effect sizes demonstrates that treatment efficacy is at best moderate. Though high effect sizes are found, these are largely within-group change effects rather then treatment effects. Moreover, the meta-analysis confirms a general lack of empirical evidence; some studies report positive treatment outcomes on the basis of incomplete information (e.g. no data), neglecting large treatment effects seen in control groups, or from inadequate research designs (e.g. without control group). Such reporting further obscures the available evidence. With so little evidence for the efficacy and effectiveness of interventions for children in areas of conflict, this field is in need of more rigorous research, as has been recommended in other reviews (Patel et al.,
2007; Morris et al., 2007; Betancourt \& Williams, 2008), and there is a complete lack of treatment mechanisms research. As noted by Patel and colleagues (2008), a weak evidence base limits our ability to infer comparative strengths and limitations of interventions and in turn to scale up interventions. The conducted studies are skewed in their primary focus on PTSDsymptoms, while several of these studies also include other indicators and few studies target different conditions altogether. The skewed focus may be explained by the fact that effect studies require the study of a specific intervention for a targeted condition, as well as by a trend among researchers to emphasize PTSD in complex emergencies. The lack of evaluations of the multifocused interventions can be explained by the methodological constraints due to combined methods and objectives.

This study confirms the weak evidence base that has been reported for child mental health in low- and middle-income settings in general (Morris et al., 2007; Barenbaum et al., 2004; Patel et al., 2008). In addition, we add an in-depth overview of reported treatment approaches and practices. Reviewing treatment modalities among both outcome studies as well as non-researched interventions enabled us to differentiate commonalities and variations, providing an overview of trends and apparent consensus within the field.

\section{Treatment modalities}

In general, we see diversity in treatment modalities depending on the targeted distress level, with some modalities such as expression/creativity and psychoeducation common across categories. Geographical representation, especially for the treatment evaluation studies, is seriously skewed towards countries formerly part of Yugoslavia. A majority of the publications reported adaptations to the cultural context of the intervention; however, the adaptations are generally minimal and briefly described or simply just recommended. Similarly, evaluations of interventions (excluding treatment outcome studies) are common within the treatment publications with almost uniformly positive results. However, they lack thoroughness by relying heavily on anecdotal information. To improve evaluation procedures in low- and middle-income countries, a number of authors call for more concentrated efforts for contextually valid assessment procedures to increase relevance of indicators, and this echoes publications not included in the review (Miller et al., 2006; Betancourt \& Williams, 2008; Jordans et al., in press).

It is noteworthy that the emphasis on PTSD among the treatment outcome studies is not applicable for the totality of articles included in the review, since all PTSD-focused articles are outcome studies. This seems to indicate that the field at large has moved away from a narrow focus on trauma while treatment outcome research remains limited in approach and target. There is an even balance of interventions targeting different well-being/distress levels, especially when considering that the majority of the multi-sectoral interventions are targeting general wellbeing. These findings agree with the increasingly advocated paradigm shift from a clinical tertiary prevention focus to primary and secondary prevention in low- and middle-income countries (De 
Table 5. Cultural adaptations in all papers $(n=66)$

\begin{tabular}{|c|c|c|}
\hline $\begin{array}{l}\text { Type of } \\
\text { adaptation }\end{array}$ & Details & $N(\%)$ \\
\hline $\begin{array}{l}\text { None } \\
\text { mentioned }\end{array}$ & N/A & $22(33.3 \%)$ \\
\hline \multirow[t]{10}{*}{ Treatment } & Discussion of cultural discrepancies in training & $17(25.8 \%)$ \\
\hline & Focus on natural healing processes & \\
\hline & Counselling instead of specialized psychotherapies & \\
\hline & $\begin{array}{l}\text { Inclusion of traditional activities with therapeutic components (dance, music, } \\
\text { storytelling, poems, indigenous coping strategies, cleansing rituals) }\end{array}$ & \\
\hline & Collaborations with traditional healers and rituals & \\
\hline & Less emphasis on therapists as neutral agents & \\
\hline & Utilisation of existing (cultural) resources & \\
\hline & Utilisation of religious practices (in grief processing) & \\
\hline & Adaptation of toys & \\
\hline & Inclusion of illustrative materials & \\
\hline \multirow[t]{4}{*}{ Assessment } & Local needs, resources and distress expressions & $5(7.8 \%)$ \\
\hline & Cultural manifestations of diagnostic categories & \\
\hline & Locally developed diagnostic/screening instruments & \\
\hline & Adaptation of research instruments & \\
\hline \multirow{7}{*}{$\begin{array}{l}\text { Program } \\
\text { development }\end{array}$} & Limit international helpers as experts & $12(18.2 \%)$ \\
\hline & Participatory approach (as opposed to imposition) & \\
\hline & $\begin{array}{l}\text { Knowledge of population's perceptions, language and related to distress } \\
\text { (mental), health and healing }\end{array}$ & \\
\hline & $\begin{array}{l}\text { Knowledge of setting specific nature/effects of warfare and perceptions of } \\
\text { meaning of conflict }\end{array}$ & \\
\hline & Adapt notions of child development & \\
\hline & Working with local professionals/partnerships & \\
\hline & Favouring collective over individualistic approach & \\
\hline Combination & Integration of several adaptations mentioned in above categories & $2(3.0 \%)$ \\
\hline \multirow{2}{*}{$\begin{array}{l}\text { Cross-cultural } \\
\text { notions of } \\
\text { existing } \\
\text { intervention } \\
\text { highlighted }\end{array}$} & $\begin{array}{l}\text { Dance \& movement (congruent with alleged not dividing of psycho and soma in } \\
\text { non-Western cultures) }\end{array}$ & $2(3.0 \%)$ \\
\hline & Narratives (congruent with traditions of story telling) & \\
\hline Others & The importance of adaptations are mentioned but no details provided & $6(9.1 \%)$ \\
\hline
\end{tabular}

Berry, 2004; Stichick, 2001; De Jong, 2002; Tolfree, 1996). These findings provide a more nuanced picture than the dichotomisation between curative/psychiatric and preventative/psychosocial interventions as outlined by other publications that have reflected on the literature of interventions for children affected by armed conflict (Betancourt \& Williams, 2008; Kalsma-van Lith, 2007). There seems to be less of a divide than is often reported. At the same time it is apparent from this literature review that a public mental health framework is frequently advocated, primarily because of lack of resources and the lower need of specialised services, yet only one actual application of a multi-levelled approach is reported (Saltzman et al., 2003). Similarly, only a few authors have published accounts of the design and implementation of multi-sectoral approaches.

Furthermore, there is emerging consensus on the adoption of community-based approaches as opposed to a clinic-based approach. An overwhelming number of the articles report or recommend community-based work. However, few studies actually elaborate on what that entails in practical terms (e.g. Wessels \& Monteiro, 2004, 2006; De Berry, 2004; Boyden, 1994) or define a community-based approach (for example, see de Jong $\&$ Komproe, 2002). Similarly, few of the overall reviewed publications elaborate on the content of the interventions and treatment approach. There are many position and policy papers or clinical programs that scarcely mention actual service delivery.

\section{Limitations}

A few limitations of the systematic review methodology should be noted. First, although categorisation of treatment approaches was based on thorough analytical procedures, the decision to assign a publication to a certain treatment category was based on its core treatment focus, which may have overlooked the overlap of different approaches in one publication (unless specifically presented as a multi-foci approach). Second, a certain overlap between approaches could not be avoided. Third, only peer-reviewed articles and chapters were included, thereby omitting a vast body of 'grey literature', with more descriptive information on interventions. For example, Tolfree (1996) is a good example of a description of multi-sectoral and practical interventions for conflict-affected children not included in the review.

\section{Conclusion}

While mostly positive, the results of the outcome studies are far from convincing. The scarcity of rigorous studies, the diversity of researched interventions, and the conditions and diversity of results make firm conclusions difficult. Though some evaluations are promising, effect sizes of controlled studies are, at best, moderate and several evaluations have serious methodological flaws. Effect studies are skewed geographi- 
cally and towards targeting PTSD-symptoms. An overview of the employed treatment modalities presents a range of interventions, with creative-expressive techniques most commonly reported. Consensus seems to be present in discourse favouring multi-levelled community-based approaches, cultural adaptations, and evaluations. However, actual adherence to these principles is not often reported or lacks depth. The field at large seems to have moved away from a narrow disorder-specific focus to a more balanced distribution of attention to general well-being, mild distress, and psychopathology. There appears to be a gap between research, policy and practice as there is a serious lack in the literature of evidence-supported interventions and presentation of applications of treatment approaches. Future efforts should be more theory driven and develop clear paradigms for dealing with psychosocial and mental health care for children, which may be challenging considering the demonstrated paradigm shift from narrow to broad programming and the lack of developed theory for the latter. Moreover, increased development of care systems, contextualised interventions, extensive research on efficacy and effectiveness of treatments, and research aimed at identifying specific working ingredients of treatments are recommended in order to create an evidence base from which psychosocial and mental health interventions can be scaled up.

\section{Acknowledgement}

This study was conducted with a grant from PLAN Netherlands. We would like to thank Vicky Verschoor and Brandon Kohrt for their contributions to this study.

\section{References}

Agani, F. (2005). Building child and adolescent mental health services in a post-war Kosovo. In M.J. Friedman \& A. Mikus Kos (Eds.), Promoting the psychosocial well being of children following war and terrorism. Amsterdam: IOS Press.

Ager, A. (2006). What is family? The nature and functions of families in times of conflict. In N. Boothby, A. Strang \& M.G. Wessels (Eds.), A world turned upside down: Social ecological approaches to children in war zones. Bloomfield, CT: Kumarian Press, Inc.

Akhundov, N. (1999). Psychosocial rehabilitation of IDP children: Using theatre, art, music and sport. Forced Migration, 6, 21-22.

Amone-P'Olak, K. (2005). Psychological impact of war and sexual abuse on adolescent girls in Northern Uganda. Intervention, 3, 33-45.

Apfel, R., \& Simon, B. (1996). Psychosocial interventions for children of war: The value of a model of resiliency. Medicine and Global Survival, 3, 1-19.

Arafat, C., \& Musleh, T. (2006). Education and hope: A psychosocial assessment of Palestinian children. In $\mathrm{N}$. Boothby, A. Strang \& M.G. Wessels (Eds.), A world turned upside down: Social ecological approaches to children in war zones. Bloomfield, CT: Kumarian Press, Inc.

Ayalon, O. (1998). Community healing for children traumatized by war. International Review of Psychiatry, 10, 224233.

Barenbaum, J., Ruchkin, V., \& Schwab-Stone, M. (2004). The psychosocial aspects of children exposed to war: Practice and policy initiatives. Journal of Child Psychology and Psychiatry, 45, 41-62.
Belfer, M. (2008). Child and adolescent mental disorders: The magnitude of the problem across the globe. The Journal of Child Psychology and Psychiatry, 3, 226-236.

Betancourt, T.S., \& Williams, T. (2008). Building an evidence base on mental health interventions for children affected by armed conflict. Intervention, 6, 39-56.

Bolton, P., Bass, J., Betancourt, T., Speelman, L., Onyango, G., Clougherty, K. F., Neugebauer, R., Murray, L., \& Verdeli, H. (2007). Interventions for depression symptoms among adolescent survivors of war and displacement in Northern Uganda. Journal of the American Medical Association, 298, 519-527.

Boothby, N. (1992). Displaced children: Psychological theory and practice from the field. Journal of Refugee Studies, 5, 106-122.

Boothby, N. (1996). Mobilizing communities to meet the psychosocial needs of children in war and refugee crisis. In R.J. Apfel \& B. Simon (eds.), Minefields in their hearts: The mental health of children in war and communal violence. New Haven: Yale University Press.

Boothby, N. (2006). When former child soldiers grow up. In N. Boothby, A. Strang \& M.G. Wessels (Eds.), A world turned upside down: Social ecological approaches to children in war zones. Bloomfield, CT: Kumarian Press, Inc.

Boothby, N., \& Halprin, J. (2005). Former Mozambican child soldiers life outcome study. In M.J. Friedman \& A. Mikus Kos (Eds.), Promoting the psychosocial well being of children following war and terrorism. Amsterdam: IOS Press.

Boyden, J. (1994). Children's experience of conflict related emergencies: Some implications for relief policy and practice. Disasters, 18, 254-267.

Brymer, M.J., Stuvland, R., \& Medway, P.J. (2005). Issues in the development of psychosocial programs for children, adolescents and families in Kosovo. In M.J. Friedman \& A. Mikus Kos (Eds.), Promoting the psychosocial well-being of children following war and terrorism. Amsterdam: IOS Press.

Chase, R., Doney, A., Sivayogan, S., Ariyaratne, V., Satkunanayagam, P., \& Swaminathan, A. (1999). Mental health initiatives as peace initiatives in Sri Lankan school children affected by armed conflict. Medicine, Conflict \& Survival, 15, 379-390.

Cohen, J. (Ed.) (1988). Statistical power analysis for the behavioural sciences (2nd ed.) Hillsdale, NJ: Erlbaum.

Cox, J., Davies, D.R., Burlingame, G.M., Campbell, J.E., Layne, C.M., \& Katzenbach, R.J. (2007). Effectiveness of a trauma/ grief-focused group intervention: A qualitative study with war-exposed Bosnian adolescents. International Journal of Group Psychotherapy, 57, 319-345.

De Berry, J. (2004). Community psychosocial support in Afghanistan. Intervention, 2, 143-151.

de Jong, J.T.V.M. (Ed.) (2002). Trauma, war, and violence: Public mental health in socio-cultural context. New York: Plenum.

de Jong, J.T.V.M., \& Komproe, I.H. (2002). Closing the gap between psychiatric epidemiology and mental health in post conflict situations. The Lancet, 359, 1793-1794.

Dybdahl, R. (2001a). Children and mothers in war: An outcome study of a psychosocial intervention program. Child Development, 72, 1214-1230.

Dybdahl, R. (2001b). A psychosocial support programme for children and mothers in war. Clinical Child Psychology and Psychiatry, 6, 425-436.

Flament, M.F., Nguyen, H., Furino, C., Schachter, H., MacLean, C., Wasserman, D., Sartorius, N., \& Remschmidt, H. (2007). Evidence-based primary prevention programmes for the promotion of mental health in children and adolescents: A systematic worldwide review. In H. Remschmidt, B. Nurcombe, M.L. Belfer, N. Sartorius \& A. Okasha (Eds.), The mental health of children and adolescents: An area of global neglect. West Sussex: Wiley \& Sons. 
Gordon, J.S., Staples, J.K., Blyta, A., \& Bytyqi, M. (2004). Treatment of post traumatic stress disorder in postwar Kosovo high school students using mind-body skills groups: A pilot study. Journal of Traumatic Stress, 17, 143-147.

Gupta, L., \& Zimmer, C. (2008). Psychosocial interventions for war affected children in Sierra Leone. British Journal of Psychiatry, 192, 212-216.

Harris, D.A. (2007). Dance/movement therapy approaches to fostering resilience and recovery among African adolescent torture survivors. Torture, 17, 134-155.

Hart, J. (2003). Children's' clubs: New ways of working with conflict displaced children in Sri Lanka. Forced Migration Review, 15, 36-39.

Hepburn, A. (2006). Running scared: When children become separated in emergencies. In N. Boothby, A. Strang \& M.G. Wessels (Eds.), A world turned upside down: Social ecological approaches to children in war zones. Bloomfield, CT: Kumarian Press, Inc.

Inter-Agency Standing Committee (IASC) (2007). IASC guidelines on mental health and psychosocial support in emergency settings. Geneva: IASC.

Jones, L., Rrustemi, A., Shahini, M., \& Uka, A. (2003). Mental health services for war-affected children. British Journal of Psychiatry, 183, 540-546.

Jordans, M.J.D., Komproe, I.H., Ventevogel, P., Tol, W.A., \& de Jong, J.T.V.M. (in press). Development and validation of the child psychosocial distress screener in Burundi. American Journal of Orthopsychiatry.

Joshi, P.T. (1998). Guidelines for international trauma work. International Review of Psychiatry, 10, 179-185.

Kalsma-Van Lith, B. (2007). Psychosocial interventions for children in war-affected countries: The state of the art. Intervention, 5, 3-17.

Kos, A.M. (2005). Activating community resources for the well being of children and stability. In M.J. Friedman \& A. Mikus Kos (Eds.), Promoting the psychosocial well being of children following war and terrorism. Amsterdam: IOS Press.

Kos, A.M., \& Derviskadic-Jovanovic, S. (1998). What can we do to support children who have been through war? Forced Migration Review, 3, 4-7.

Kos, A.M., \& Huzejrovic, V. (2003). Volunteers as helpers in war-related distress. Intervention, 1, 50-56.

Kos, A. M., \& Zemljak, B. (2007). Psychosocial support for children, families and teachers in Iraq. Intervention, 5, 150158 .

Kostelny, K. (2006). A culture-based, integrative approach: Helping war-affected children. In N. Boothby, A. Strang \& M.G. Wessels (Eds.), A world turned upside down: Social ecological approaches to children in war zones. Bloomfield, CT: Kumarian Press, Inc.

Layne, C.M., Pynoos, R.S., Saltzman, W.R., Arslanagic, B., Black, M., Savjak, N., Popovic, T., Durakovic, E., Music, M., Campara, N., Djapo, N., \& Houston, R. (2001). Trauma/ grief-focused group psychotherapy: School-based postwar intervention with traumatized Bosnian adolescents. Group Dynamics: Theory, Research, and Practice, 5, 277-290.

Loughry, M., Ager, A., Flouri, E., Khamis, V., Afana, A.H., \& Qouta, S. (2006). The impact of structured activities among Palestinian children in a time of conflict. Journal of Child Psychology and Psychiatry, 47, 1211-1218.

Lykes, M.B. (1994). Terror, silencing, and children: International multidisciplinary collaboration with Guatemalan Maya communities. Social Science \& Medicine, 38, 543-552.

McKay, S. (2006). Girlhoods stolen: The plight of girl soldiers during and after armed conflict. In N. Boothby, A. Strang \& M.G. Wessels (Eds.), A world turned upside down: Social ecological approaches to children in war zones (pp. 89-111). Bloomfield, CT: Kumarian Press, Inc.

Miller, K.E., \& Billings, D.L. (1994). Playing to grow: A primary mental health intervention with Guatemalan refugee children. American Journal of Orthopsychiatry, 64, 346-356.
Miller, K.E., Omidian, P., Quraishy, A.S., Quraishy, N., Karyar, N.M., \& Yaqubi, A.A. (2006). The Afghan symptom checklist: A culturally grounded approach to mental health assessment in a conflict zone. American Journal of Orthopsychiatry, $76,423-433$.

Minkowski, A. (2000). Protection of the young child's brain: Personal observations and thoughts in post war stress syndrome and in natural catastrophes. Acta Paediatrica, 89, 378-385.

Morris, J., Van Ommeren, M., Belfer, M., Saxena, S., \& Saraceno, B. (2007). Children and the Sphere standard on mental and social aspects of health. Disasters, 31, 71-90.

Moss, W.J., Ramakrishnan, M., Storms, D., Siegle, A.H., Weiss, W.M., Lejnev, I., \& Muhe, L. (2006). Child health in complex emergencies. Bulletin of the World Health Organization, 84, 58-64.

Olij, J. (2005). Trauma awareness, healing and group counselling in secondary schools. Intervention, 3, 51-56.

Onyut, LP., Neuner, F., Schauer, E., Ertl, V., Odenwald, M., Schauer, M., \& Elbert, T. (2005). Narrative exposure therapy as a treatment for child war survivors with post traumatic stress disorder: Two case reports and a pilot study in an refugee settlement. BMC Psychiatry, 5, 7.

Paardekooper, B.P. (2002). Children of the forgotten war: A comparison of the two intervention programs for the promotion of well-being of Sudanese refugee children. Dissertation. Amsterdam: Vrije Universiteit.

Patel, V., Araya, R., Chatterjee, S., Chisholm, D., Cohen, A., De Silva, M., Hosman, C., McGuire, H., Rojas, G., \& van Ommeren, M. (2007). Treatment and prevention of mental disorders in low-income and middle-income countries. The Lancet, 370, 991-1005.

Patel, V., Flisher, A.J., Nikapota, A., \& Malhotra, S. (2008). Promoting child and adolescent mental health in low- and middle-income countries. Journal of Child Psychology and Psychiatry, 49, 313-334.

Remschmidt, H., Nurcombe, B., Belfer, M.L., Sartorius, N., \& Okasha, A. (Eds.) (2007). The mental health of children and adolescents. An area of global neglect. West Sussex: Wiley \& Sons.

Reynolds, P. (1996). Children of tribulation: The need and means to heal war trauma. In P. Reynolds, Traditional healers and childhood in Zimbabwe. Athens, OH: Ohio University Press.

Saltzman, W.R., Layne, C.M., Syeinberg, A.M., Arslanagic, B., \& Pynoos, R.S. (2003). Developing a culturally and ecologically sound intervention program for youth exposed to war and terrorism. Child and Adolescent Psychiatric Clinics North America, 12, 319-342.

Schauer, E., Neuner, F., Elbert, T., Erlt, V., Onyut, L.P., Odenwalt, M., \& Schauer, M. (2004). Narrative exposure therapy in children: A case study. Intervention, 2, 1832 .

Shaw, J.A., \& Harris, J.J. (1994). Children of war and children at war: Child victims of terrorism in Mozambique. In R.J. Ursano \& B.G. McCaughey (Eds.), Individual and community responses to trauma and disaster: The structure of human chaos. Cambridge: Cambridge University Press.

Simó-Algado, S., Mehta, N., Kronenberg, F.C.W., Cockburn, L., \& Kirsh, B. (2002). Occupational therapy interventions with children survivors of war. Canadian Journal of Occupational Therapy, 69, 4.

Stichick, T. (2001). The psychosocial impact of armed conflict on children: Rethinking traditional paradigms in research and intervention. Child and Adolescent Psychiatric Clinics of North America, 10, 797-814.

Stichick-Betancourt, S. (2005). Stressors, supports and the social ecology of displacement: Psychososical dimensions of an emergency education program for Chechen adolescents displaced in Ingushetia, Russia. Culture Medicine and Psychiatry, 29, 309-340. 
Thabet, A.A., Vostanis, P., \& Karim, K. (2005). Group crisis intervention for children during ongoing war conflict. European Child \& Adolescent Psychiatry, 14, 262-269.

Tolfree, D. (1996). Restoring playfulness. Different approaches to assisting children who are psychologically affected by war or displacement. Falun: Radda Barnen.

Tribe, R. (2004). A critical review of the evolution of a multilevel community-based children's play activity programme run by the Family Rehabilitation Centre (FRC) throughout Sri Lanka. Journal of Refugee Studies, 17, 114-135.

Triplehorn, C., \& Chen, C. (2006). Layers of support: The social ecology of protecting children in war. In N. Boothby, A. Strang \& M.G. Wessels (Eds.), A world turned upside down: Social ecological approaches to children in war zones. Bloomfield, CT: Kumarian Press, Inc.

Veale, A., \& Dona, G. (2002). Psychosocial intervention and children's rights: Beyond clinical discourse. Journal of Peace Psychology, 8, 47-61.

Wertheim-Cahen, T., Euwema, M., \& Nabarro, M. (2005). Trees coloured pink. The use of creativity as a means of psychosocial support for children in Kosovo: An ongoing learning process. Intervention, 3, 112-121.

Wessels, M. (2006). A living wage: The importance of livelihood in reintegrating former child soldiers. In N. Boothby, A. Strang \& M.G. Wessels (Eds.), A world turned upside down: Social ecological approaches to children in war zones. Bloomfield, CT: Kumarian Press, Inc.

Wessels, M., \& Monteiro, C. (2006). Psychosocial assistance for youth: Towards reconstruction for peace in Angola. Journal of Social Issues, 62, 121-139.

Wessels, M.G., \& Monteiro, C. (2004). Healing the wounds following protracted conflict in Angola: A community-based approach to assisting war-affected children. In U.P. Gielen, J.M. Fish \& J.G. Draguns (Eds.), Handbook of culture, therapy, and healing. Mahwah, NJ: Lawrence Erlbaum Associates, Inc.

Wexler, I.D., Branski, D., \& Kerem, E. (2006). War and children. Journal of the American Medical Association, 296, $579-581$

Wiley-Exley, E. (2007). Evaluations of community mental health care in low- and middle income countries: A 10 year review of the literature. Social Science \& Medicine, 64, 12311241.

Williams, R. (2006). The psychosocial consequences for children and young people who are exposed to terrorism, war, conflict, and natural disasters. Current Opinion in Psychiatry, 19, 337-349.

Woodside, D., Santa Barbara, J., \& Benner, D.G. (1999). Psychological trauma and social healing in Croatia. Medicine, Conflict and Survival, 15, 355-367.

World Bank (2007). Data and statistics (http://web.worldbank.org/) Accessed 2/4/2008.

Yule, W. (2000). Emanuel Miller lecture. From pogroms to 'ethnic cleansing': Meeting the needs of war affected children. Journal of Child Psychology and Psychiatry, 41, 695702 .

Yule, W. (2002). Alleviating the effects of war and displacement on children. Traumatology, 8, 160-181.

Yule, W., Stuvland, R., Baingana, F., \& Smith, P. (2003). Children in armed conflict. In B.L. Green, M.J. Friedman, J.T.V.M. de Jong, S. D. Solomon, T.M. Keane, J.A. Fairbank, B. Donelan \& E. Frey-Wouters (Eds.), Trauma interventions in war and peace. Prevention, practice and policy. New York: Kluwer Academic/Plenum Publishers. 